\title{
The Common Vision Project: Four Reactions
}

\section{Communicated by Harriet Pollatsek}

The Common Vision project seeks to modernize undergraduate programs in the mathematical sciences, especially courses taken in the first two years. It is a joint effort of the American Mathematical Association of Two-Year Colleges, the American Mathematical Society, the American Statistical Association, the Mathematical Association of America, and the Society for Industrial and Applied Mathematics. Their report ${ }^{1}$ reflects a synthesis of common themes in seven curricular guides published by these five associations along with more recent research and input.

The report calls on the community to:

(1) update curricula,

(2) articulate clear pathways between curricula driven by changes at the $\mathrm{K}-12$ level and the first courses students take in college,

(3) scale up the use of evidence-based pedagogical methods,

(4) find ways to remove barriers facing students at critical transition points (e.g., placement, transfer), and

(5) establish stronger connections with other disciplines.

It urges institutions to provide faculty with training, resources, and rewards for their efforts to meet these goals.

The Notices asked four mathematicians to write short pieces summarizing their reactions to the Common Vision report. These pieces appear below.

\section{www.maa.org/common-vision}

For permission to reprint this article, please contact: reprint-permission@ams . org.

DOI: http://dx.doi.org/10.1090/noti1482

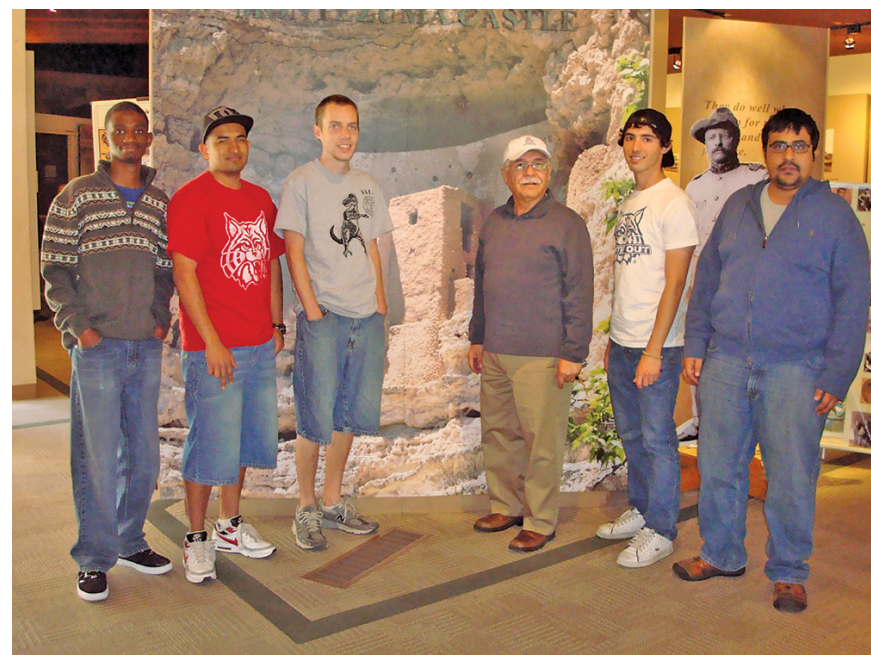

A group of students from the University of Arizona with William Yslas Vélez at Montezuma Castle National Monument. They were en route to the 2011 SUNMARC conference at Northern Arizona University.

\section{William Yslas Vélez}

A document that brings together the thoughts of different mathematical societies into one united vision is certainly useful. This is especially important when these societies express a common vision. The data presented in the

William Yslas Vélez is University Distinguished Professor, associate head for undergraduate affairs, and Math Center director at the University of Arizona. His e-mail address is velez@math. arizona.edu. 
introduction are compelling and serve notice that much needs to be done to be more inclusive.

As someone who has devoted considerable energy to increasing diversity in mathematics and inThere appears to be a disconnect between what the societies think is important and how rank-and-file faculty operate. creasing the number of mathematics majors, I am well aware of the content described in the first thirty pages of only one piece of information that I found surprising: "A primary point emphasized by all the guides is that the status quo is unacceptable." this report. There was

My opinion is that faculty do not seem to have bought into such a strong statement. There appears to be a disconnect between what the societies think is important and how rank-and-file faculty operate. I give talks to many mathematics departments and regularly am part of academic program reviews of departments, yet I don't encounter such strong feelings expressed during those interactions.

This difference is reflected in the section on "Scaling." The authors pose three questions concerning the issue of sustainability/transportability of successful programs. I think that to these three questions must be added the first question: "How do we get departments interested in these questions?" How do we convince departments that they should reallocate their limited resources to address these questions when they have so many other pressing matters to address?

The last section on "Moving Forward" is of central importance. Indicating what the problems are is the first step; the second step should be how to mobilize departments to be concerned about finding solutions to these problems. Then and only then will we be able to begin to develop solutions.

In looking toward the future, we recognize that departments have different missions and that the issues they choose to address will be different, depending upon their goals. Bachelor's-granting institutions are not the same as doctoral-granting institutions. However, they have one thing in common. Doctoral mathematical science departments train all these faculty, and it is this training that should be central to moving forward.

In an opinion piece in the 2015 June/July Notices, I spoke of gathering data on our graduate programs, and I want to promote that idea again here because of its impact on creating the next generations of faculty. Departments should record where their graduates are going. If these graduates are going into the teaching profession, then their training should reflect this path. On-the-job training in the many facets indicated in this Common Vision is simply not practical. If all a student sees in their graduate training is the standard lecture format and lack of technology in the teaching of mathematics, how do we expect these same new faculty to adopt new teaching techniques? Those departments that have a higher percentage of graduates pursuing teaching should be taking the lead in providing the training that is necessary to move forward.

\section{Amy Cohen}

Although "workforce preparation and faculty development" is one of the four areas identified as requiring "significant further action," it is not until page 26 that the Common Vision report mentions changes in instructional staffing over the last two decades that challenge the achievement of the project's goals and more generally challenge our profession.

Tenured research-active faculty members now teach a smaller proportion of students in the calculus sequence, linear algebra, and differential equations. ${ }^{2}$ Their place is increasingly taken by full-time non-tenure-track (FT NTT) doctoral faculty or by graduate students. Hiring in the category of FT NTT doctoral faculty by PhD-granting departments is growing. Hiring of "tenure-eligible" faculty has stagnated since 2008. Even upper-level math major courses in universities are frequently taught by FT NTT mathematicians.

Departmental culture and policy about course offerings, hiring, and promotion are still set by tenured faculty. FT NTT faculty with teaching loads of four courses per term cannot reasonably be expected to design or implement new courses, coordinate courses, do advising, and/ or mentor new colleagues without support from senior faculty.

The growing enrollment in mathematics from sophomore year onward is largely driven by the lure of a growing STEM workforce. Students whose primary majors are outside math realize that a second major or a strong minor in math will enhance their preparation for graduate education and/or employment after college. Mathematicians whose undergraduate studies were in elite schools (inside or outside the United States) are often surprised that future high school teachers of mathematics enroll in upper-level math courses (e.g., analysis, algebra, geometry, and/or probability) alongside future engineers, microbiologists, and economists.

Mathematicians recognize the power of generalization and abstraction for a broad variety of applications. Undergraduates need to learn how to generalize from the concrete to the abstract and then how to specialize back to concrete problems. Pure mathematicians may have difficulty in teaching this process successfully without

Amy Cohen is professor of mathematics (emerita) at Rutgers University. Her e-mail address is acc@math. rutgers. edu.

${ }^{2}$ R. Blair, E. Kirkman, J. Maxwell, Statistical Abstract of Undergraduate Programs in the Mathematical Sciences in the US, Conference Board of the Mathematical Sciences, AMS, 2013. See also Cohen's article on "Disruptions of the academic math employment market" in the October 2016 Notices. 
a culture of professional development including collaboration across disciplines. Without concurrent "faculty development" I fear that the new courses the Common Vision report advocates, if they find instructors at all, may fail for lack of effective instruction.

What forms might effective faculty development take? Professional societies in the mathematical sciences sponsor relevant conference sessions, short courses, and related projects. A very limited fraction of faculty (whether on tenure track or not) find institutional funding to participate. Professional societies should offer such programs also at their local and regional meetings. Individual institutions and their statewide systems could do the same. Online professional learning communities potentially offer another mode of outreach. Collaboration among university administration, departmental leadership and faculty, and funding sources is essential so that faculty development occurs and improves teaching and learning in undergraduate mathematics.

\section{Priscilla Bremser}

The Common Vision report puts forth an ambitious agenda for change in mathematics instruction. It sets expectations for administrators, departments,
How might we design a workshop grounded in modern understanding of how people learn? and instructors, some of whom will need to be convinced that their participation is vital. Fortunately, the report is a collaborative effort, endorsed by all of the relevant major professional organizations. That in itself is no guarantee of success, however. The community, meaning those of us who are eager to move into the implementation phase, will have to be intentional and creative in approaching our work. In order to modernize undergraduate programs in the mathematical sciences, we must bring modern approaches to curricular design, professional development, and outreach activities.

The verdict that “the status quo is unacceptable" won't get much argument from the various constituencies. The data presented in the report confirm what we all know: too many college students fail mathematics courses, and too many others lose interest in mathematics. To its credit, the report does not place blame for the situation on any group. Chapter 3, "Moving Forward," presents concrete "ways in which faculty members, deans, and other administrators can create an environment that supports improvements in undergraduate mathematical sciences education" (page 31).

Priscilla Bremser is professor of mathematics at Middlebury College. Her e-mail address is bremser@midd1 ebury. edu.
In the "Course Structure" section of the report the authors identify "a general call to move away from the use of a traditional lecture as the sole instructional delivery method in undergraduate mathematics courses." The evidence for the efficacy of active-learning approaches is strong and growing; it should inform our professional development efforts as well. I'm encouraged that the term "workshop" appears often in Chapter 3, but I've participated in "workshops" that were essentially lectures and minimally effective as a result. How might we design a workshop grounded in modern understanding of how people learn? If we insist that the goal of a short course be not mere transmission of information but rather genuine cognitive engagement with the problem at hand, what changes in format and execution can we expect to see?

For that matter, how might we invite administrators to be active participants in the improvements we seek? At the end of the first year in the Vermont Mathematics Initiative, a professional development program for teachers, each teacher is required to bring a supervising administrator to a leadership training retreat. It's intriguing to imagine a Modeling Across the Curriculum workshop on economic mobility with deans working alongside faculty and students. Instead of poster sessions for policymakers, how about bring-your-own-data service-learning projects, where statistics students and faculty work with legislators to interpret information relevant to current issues?

A corollary then to "the status quo is unacceptable" is this: traditional ways of promoting improvements in undergraduate mathematics education are not enough. Our potential collaborators in and out of the academy will not hop on board if all we offer is a passive experience, whether it's a printed report, a PowerPoint presentation, or a MOOC. Instead, let's invite them into carefully structured and intellectually challenging activities.

\section{Douglas Mupasiri}

The Department of Mathematics at the University of Northern Iowa, of which I am head, has just undergone its required septennial academic program review, and that process has brought the issues discussed in the Common Vision project into sharp focus. Here I discuss four of the biggest challenges I see, organized by the themes mentioned in all seven guides written by the five professional associations that participated in the Common Vision project. I also consider student diversity, mentioned in some but not all the guides.

Curricula: It is hard to see how departments will be able to modernize their curricula in the ways contemplated in the report without an infusion of new resources. Many departments will have to make some hard choices about which changes to make and which not, based on their local contexts. An essential part of any effort with a chance of succeeding will be developing appropriate curriculum models for different types of institutions, publicizing and disseminating them, and then scaling them up.

Douglas Mupasiri is professor of mathematics at the University of Northern Iowa. His e-mail address is mupasi ri@math . uni . edu. 


\section{The onus is}

on the entire mathematical sciences community to heed the call.
Course structure: Most mathematics faculty still use the traditional lecture, but there is increasing recognition of the need for change to more active forms of instruction (Freeman et al., 2014). The recently published CBMS statement on active learning is but the latest example. The projects Progress through Calculus, Transforming-Post Secondary Education in Mathematics, and others are promising efforts to address this challenge.

Workforce preparation: Should mathematical sciences departments train their students for specific jobs or concentrate their attention on providing them with the competencies and critical thinking skills that will give them the flexibility to successfully move from one job to another? The fact is: It is possible to do both. Departments can complement their existing course offerings with devices such as guided research and strategically arranged internships to design programs that aim to "narrow the gap between today's mathematics as it is practiced in the academy, industry and government and how it is experienced in higher education's instructional programs."3

Student diversity: The authors of the Common Vision report write, "The fact that our community has been unable to attract and retain a diverse student population in the mathematical sciences is a dreadful shortcoming that must be remedied." Beyond the moral case for recruiting students from groups that have been traditionally underrepresented in the mathematical sciences, including women, there is growing consensus that there is also an economic and national security imperative. But addressing this issue won't be easy, as anyone who has tried it will attest. There are, however, some potentially hopeful signs on the horizon. Increasing press coverage of the growing income gap between the rich and the poor the world over is bringing more attention to this issue. Professional organizations are also giving greater focus to the matter. The AMS recently named Helen G. Grundman director of its newly created Department of Education and Diversity. SIAM has a Diversity Advisory Committee.

The Common Vision project has brilliantly laid a predicate for a compelling call to action. The onus is on the entire mathematical sciences community to heed the call. "Are we equal to the challenge?" I think yes.

Related Notices articles:

A Common Vision for Undergraduate Mathematics, by Tara Holm and Karen Saxe, June/July, 2016.

Are Mathematics Faculty Ready for Common Vision? by Marcus Jorgensen, November 2016.

What Does Active Learning Mean for Mathematicians? by Benjamin Braun, Priscilla Bremser, Art M. Duval, Elise Lockwood, and Diana White, February 2017.
Also:

AMS Blog On Teaching and Learning Mathematics, September 10, 20; October 1, 10, 2015.

\section{Photo Credits}

Photo of William Yslas Vélez and students is courtesy of William Yslas Vélez.

Photo of William Yslas Vélez is courtesy of William Yslas Vélez.

Photo of Douglas Mupasiri is courtesy of Douglas Mupasiri. Photo of Amy Cohen is courtesy of Cecilia Arias.

Photo of Priscilla Bremser is courtesy of Priscilla Bremser.

\section{ABOUT THE AUTHORS}

William Yslas Vélez has a simple goal in life: to convince every student at his university to be a math major or math minor.

Amy Cohen's major mathematical interests are PDEs with soliton solutions and making education in mathematics more satisfying for faculty as well as for students.

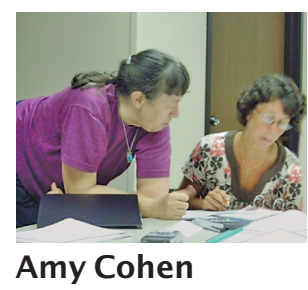

Priscilla Bremser enjoys bicycling, cross-country skiing, and hiking in Vermont.

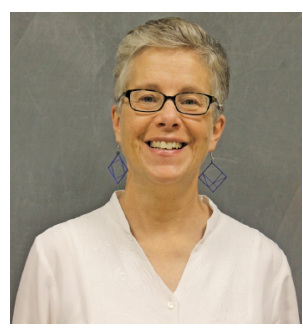

Priscilla Bremser

Douglas Mupasiri has been on the faculty of the University of Northern Iowa for twenty-three years and head of the department of mathematics for the past six years. He was born in Zimbabwe and came to the United States to go to college and eventually became a naturalized citizen.

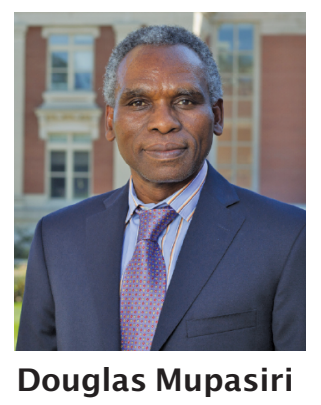

\footnotetext{
${ }^{3}$ From the Executive Summary of the Common Vision Report.
} 